\title{
Conflicts between employee preferences and ergonomic recommendations in shift scheduling: regulation based on consent is not sufficient
}

\author{
Johannes G ärtner \\ Vienna University of Technology. Wien Austria
}

\section{Keywords}

Work hours. Workers. Shift work. Decision making. Occupational health. Employment. Salaries and fringe benefits. Risk factors.

\section{Descritores}

Jornada de trabalho. Trabalhadores. Trabalho em turnos. Tomada de decisões. Saúde ocupacional. Emprego. Salários e benefícios. Fatores de risco.

\section{Abstract}

\section{Objective}

Contribution to the discussion of the role of participation/consent of employees in working hours regulation.

\section{Methods}

Exploratory analysis of conflicts between preferences of employees and ergonomic recommendations in shift scheduling by analysing a large number of participative shift scheduling projects.

\section{Results}

The analysis showed that very often the pursuit of higher income played the major role in the decision making process of employees and employees preferred working hours in conflict with health and safety principles.

\section{Conclusions}

First, the consent of employees or the works council alone does not ensure ergonomically sound schedules. Besides consent, risk assessment procedures seem to be a promising but difficult approach. Secondly, more research is necessary to check the applicability of recommendations under various settings, to support the risk assessment processes and to improve regulatory approaches to working hours.

\section{Resumo}

\section{Objetivo}

Contribuir para a discussão do papel da participação/consentimento dos empregados na regulamentação das horas de trabalho.

\section{Métodos}

Realizou-se um estudo exploratório dos conflitos existentes entre as preferências dos empregados e as recomendações ergonômicas no planejamento de esquemas de trabalho em turnos, analisando-se um grande número de projetos participativos de planejamento dos turnos.

\section{Resultados}

O estudo mostrou que, com freqüência, a busca por um rendimento maior teve um papel importante no processo de tomada de decisão dos empregados, quando estes optaram pelas horas de trabalho em oposição aos princípios de saúde e segurança. Conclusões

Em primeiro lugar, o consentimento dos empregados ou da comissão de trabalhadores

\section{Correspondence to:}

Johannes Gärtner

Presented at the XVI International Symposium on N ight and Shiftwork, N ovember 2003. Santos, SP, Brazil. Received on 15/3/2004. Approved on 27/9/04. 
por si só não garante horários salutares do ponto de vista ergonômico. Além do consentimento, processos de avaliação de risco parecem ser uma abordagem promissora embora complicada. Em segundo lugar, fazem-se necessários mais estudos para verificar a aplicabilidade das recomendações em diversas situações, respaldar os processos de avaliação de risco e melhorar as abordagens regulamentares para as horas de trabalho.

\section{INTRODUCTION}

Participation of employees in decisions concerning their living and working conditions is an important issue in many fields, including working time arrangements. Barton et $\mathrm{al}^{1}$ conclude that: "... individual control of work hours does appear to influence the degree to which problems associated with shiftwork may be experienced." Barton ${ }^{2}$ compared permanent night work and rotating-shift work of nurses and found "fewer health, sleep, social, and domestic complaints were reported by the permanent night shift nurses in comparison with the rotating-shift nurses, and these problems were further reduced when individuals in the night shift had specifically made the decision to work at night." When comparing the consequences of different shift systems, Smith et al ${ }^{10}$ state that "The situation is not a simple one of 8 versus 12-hour shifts but rather one of how features of a rota are changed, how a new shift system is implemented, and the involvement in, and attitudes of the workforce to that change." Smith et $\mathrm{al}^{11}$ conclude that their study further supports the concept of shiftwork-specific locus of control as an indicator of better tolerance to shiftwork.

Summing up, there is substantial evidence that participation or even self-determination is an important issue in improving working and living conditions.

At the same time, there is a well established body of research showing substantial differences between working time models with respect to their consequences on health and safety, for example in relation to the number of night shifts worked, the number of hours worked per day and per week (see Wedderburn ${ }^{15}$; $\mathrm{Knauth}^{8}$ ). It is accepted that different schedules have different consequences and there is no single best way to organise shiftwork. It is also accepted that the impact of organising shiftwork and consequences of many variables involved (occupation, working environment, gender, and age to name just a few) are not fully understood (Spurgeon ${ }^{12}$ ).

Furthermore there are arguments for limiting individual choice:

\section{1) Assessments by employees can be erroneous}

There are several arguments that employees might not properly assess the potential impact of the shift schedule on their health and safety:

- Persons working shifts for long periods are likely to be better able to cope while others drop out or do not start such work, producing the so-called "healthy shift worker effect" (Yadegarfar et $\mathrm{al}^{16}$ ). The assessment of health effects can therefore be expected to be conservative.

- Employees may wrongly assess the potential consequences of shiftwork for emotional or cognitive reasons. People may not be able to correctly assess other options if they have never worked or been exposed to other systems

- The effects of shift work in general are typically long term and afflict a limited number of persons. Therefore these potential effects are not obvious to the individual worker (Gärtner et al, ${ }^{6}$ 1998). Furthermore, once these long-term effects become apparent, they cannot be immediately reversed - if at all - by a change in shift schedule.

- The cost, effort and skills involved in information collection and assessment are high. Therefore many employees will not be able to make informed decisions

- Even if employees are provided with adequate information, research has shown that knowledge and behavior do not always conform (e.g., with respect to financial decision making - Freddie $\mathrm{Mac}^{5}$ ). The motivation to increase income may result in neglecting other important variables such as health and safety.

\section{2) Employees could be forced to work schedules they do not want}

Managers are typically able to exert pressure on employees to work specific hours. Depending on the situation, employees will be able to resist this pressure to different degrees. Issues of labour market, costs for employees to switch employers, literacy, and the like will influence the negotiating position of employees. While these shortcomings are reduced, they do not vanish if the consent of representatives of the 
workforce, or the workforce as a whole, is mandatory.

\section{3) Externalisation of costs}

Decisions made by employees and employers may have consequences for third parties. Costs may be externalised e.g., if they employers and employees go for a system that increases health hazards, most of the costs typically are to be paid by others (for example, by the social security and pension system). Such externalisation of costs is not in the public interest.

Based on the competing arguments presented, there is a strong justification for considering the preferences of employees, while at the same time ensuring that at least minimal ergonomic standards to protect safety and health are maintained.

Within the European Union, the working time directive (European Union, ${ }^{4}$ 1993) plays a crucial role for shaping national laws on working hours. While defining strict limits it allows national laws to dramatically relax almost all restrictions provided employees, works-councils or trade unions provide consent. Such relaxation might even make very long working hours legally possible (i.e., more than 48 hours per week).

In the present paper, I start with the review a large number of shiftwork projects in which the preferences of shiftworkers conflicted with recommendations from experts. The term 'recommendation' is from here onwards used as an abbreviation for recommendations regarding the design of shiftwork that are widely supported by the scientific community (see, for example, Colquhoun et $\mathrm{al}^{3}$ ). The results of this analysis show that there are conflicts and that these conflicts are often connected to income.

Building on these results, I argue that a regulatory approach based on consent does not suffice to ensure that minimal standards to protect safety and health are maintained. Finally I discuss a supplementary approach towards working hours regulation that revolves around the concept of risk assessment and examine consequences for future research.

\section{METHODS}

The following analysis focuses on conflicts between preferences of employees and recommendations for shift scheduling within companies. Approximately 300 projects are analysed.

These projects were performed between 1996 and 2004. While most of these projects were undertaken in Austria and Germany, some were conducted in other
European countries (for example, the UK), and outside Europe. Approximately half of them were in industrial settings (for example, in the metal and chemical industries) while others were in various service industries (for example, health and social services, call centres, transport). Sometimes the schedules were designed for very few employees (for example, less than 10), whereas in other cases the schedules were for a large number of employees (for example, several hundreds). The size of the companies also varied from relatively small ones (less than 20 employees) to large ones (more than 10,000). Most of the companies involved had between 250 and 2,000 employees.

Our company conducted the projects in a consulting capacity. There are rather different approaches to consulting. The approach used in these projects has the following specifics.

- In more than 75 per cent of the cases management paid the consultant. In most other cases trade unions and management paid. In a few cases the works council or the trade union paid. The initial contact was very often made due to a recommendation from the works council or a trade union.

- The explicit aim of engaging consultants was to find broadly accepted solutions (that is, "Win-Win" solutions). The objective was to achieve solutions that were as good as possible from an ergonomic point of view. Bargaining, for example on wage rates or supplements, was rarely part of these projects.

- The projects were participatory. They typically entailed workshops of approximately 10 to 15 persons, involving managers, members of the works council and usually a few employees. The number of workshops per project varied considerably (from a few full day workshops to more than 10 days). The existing shift schedule was analysed within the working groups and alternatives were developed and discussed.

- The consultant's main task was to develop proposals for new shift schedules based on the wishes of the participants. This was feasible as we use specialised software (Wahl et $\mathrm{al}^{14}$ ) that allows interactive development and assessment of shift schedules. Furthermore the consultant brought in expert knowledge on ergonomic recommendations and, in most cases, on legal requirements. Evaluation of schedules and the selection of a new schedule were done by the working group, not by the consultant.

- Consultants actively asked for the opinion of participants regarding the shift schedules under discussion. Participants often asked their colleagues' opinions of the various proposals between meetings.

- When the working group agreed on a specific schedule, consultants sometimes supported the development of a corresponding written agreement. 
There was little involvement in the actual implementation. However, quite often the consultant was called back in again after a year or two for further refinements or adaptations.

- All participants were continuously involved in the discussion and detailed minutes of the meetings were recorded. Participants were asked to check whether these minutes correctly reflected their (sometimes opposing) points of view. The minutes of the workshops are the basis for the following case analysis.

The reasons for bringing in consultants varied. Important issues included increases of operating hours, improving the fit between actual staffing and demand, resolving complaints from employees regarding bad working conditions and compliance with the law.

From a methodological point of view, this is an exploratory analysis. It cannot be assumed that the series of conflicts between worker preferences and ergonomic criteria identified here is comprehensive or that the probability of a specific conflict arising can be estimated. Sampling was based purely on whether our company was engaged for a consultancy and, although the analysis is based on a reasonably diverse sample (encompassing several industries, various company sizes, etc), the cases examined may not provide a representative sample of shift work systems and the results may not generalise to a wider population. However, the conflicts discussed below are clearly not unique, each having arisen in a similar form in multiple cases.

It is reasonable to conclude that conflicts were discussed relatively openly in these workshops. It was work on real issues and had substantial consequences for those involved. Consultants tried to foster open discussion. Furthermore, given the strong legal position of most works councils involved, the interest in participating in these workshops, and the active discussions, it may be assumed that in most cases the "real issues" were on the table.

\section{RESU LTS}

The decision-making processes in these cases were strongly influenced by general issues of industrial relations and relevant labour laws. There were enormous differences in problems experienced between branches, groups of employees and countries. However diverse the settings were, a common issue was that employees' preferences were in conflict with ergonomic recommendations. The following list describes only this type of issue (and not, for example, instances when employers' preferences were in conflict with ergonomic recommendations).

\section{Issue 1: Overtime}

In a number of cases (approximately 20 per cent), employees worked substantial overtime. This overtime often led to long shifts (sometimes up to 12 hours per week or even more) and correspondingly led to a reduced number of hours of rest between shifts. In the cases where shifts were short, overtime resulted in reduced periods of breaks (a higher number of working hours on $8 \mathrm{~h}$ shifts led to a higher number of shifts per week and correspondingly fewer days off per week). In most cases encountered, participants in the workshops agreed that these hours were long and demanding, causing stress and fatigue as well as increased risks of accidents.

However, despite this evaluation, only in a few cases did employees actually prefer a shortening of working hours, as they generally considered the higher income to be more important. In most cases it was managers wanting to reduce overtime to comply with health and safety principles or laws or reduce the cost of overtime supplements. In many cases members of the works council and, to a lesser degree, unionists supported employees in favouring higher wages. When opposing the preferences of employees, members of the works council and unionists offered health or reduction of unemployment as their main reasons.

\section{Issue 2: Permanent night work}

In a smaller number of cases (approximately 5 per cent) the issue of permanent night work of one group of employees was addressed. Permanent night work was generally considered unhealthy, even though this was sometimes disputed. The main reason for preferring permanent night work was income, even though in several projects other reasons were more important (e.g., sleep). Most of the managers did not show a preference for or against permanent night work and for those that preferred it, it was sometimes for organisational or employment reasons. Some managers opposed permanent night work, as they faced difficulties with management issues (not enough supervision, drug abuse, disciplinary problems and production quality) or they were concerned about health and safety. Works councils were split on that issue. Some of them considered health risks to be a reason for change. Others were in support of permanent night work, as otherwise larger parts of the work force would have to do night work. Similarly, some members of works councils who were in support of permanent night work considered preferences of employees to be more important than ergonomic recommendations. 


\section{Issue 3: Shorter daily breaks and longer weekly breaks}

In approximately 15 per cent of the cases very short breaks between shifts (less than 12h and sometimes only $8 \mathrm{~h}$ ) were introduced in order to allow longer periods of time off between series of shifts. This arrangement typically went hand in hand with long working hours and overtime, as a higher number of hours of work left little latitude for longer weekly breaks if rest hours between shifts were not shortened. The employees' preferences for these practices were based on increased overtime and the corresponding increase in income they offered.

\section{Issue 4: Slow or fast rotation}

In more than 50 per cent of cases the question of whether slow or fast rotation was preferable came up. In most cases those concerned accepted the recommendation that rapid forward rotation was superior. In cases where shifts were relatively short (for example, drivers in public transport) or where overtime was involved, fast forward rotation would have caused a shortening of rest breaks between successive shifts. In these cases forward rotation was considered to be less important than longer periods off between series of shifts.

Only in a very small number of cases other reasons for preferring slow or fast rotation were given. Childcare and further education were the main reasons for preferring a stable or slowly rotating shift-system.

\section{Issue 5: Shift length}

In a few cases the question of long shifts (e.g., 12 hours) versus shorter shifts arose. In most of these cases it was brought up in conjunction with overtime issues and the arguments matched those mentioned above. In a few cases issues of time-off, family life, opportunity to recover from emotionally demanding work, and commuting were the main reasons discussed. Managers stressed efficiency and to a lesser degree health issues in justifying their preference for shorter shifts. In cases of variable workforce demand over the day, shorter shifts were preferred, in order to meet demand more precisely. Works councils and unionists typically shared the viewpoint of employees.

\section{Issue 6: Individual choice of shifts versus a common roster}

In a few cases there were fierce discussions as to whether a roster based on personal preferences or a more general schedule should be chosen. In most of these cases this went hand in hand with questions about permanent night work and overtime, or with significant restrictions on possible working times for some of the employees involved. When there was little potential impact on income, the discussion was less fervent and the issues were principally individual preferences, the feasibility of the planning procedures to be applied and whether flexibility from the employer was important. Very different solutions were agreed (ranging from free scheduling by the employees themselves to regular rosters) depending on preferences and specific conditions (for example, the diversity of preferences or the predictability of changes in demand).

Concerning the general attitude and viewpoints of employees and members of the works council the following generalisations can be made:

1) Income is the major source of conflict between employee preferences and ergonomic recommendations

In the analysis above, income emerged as the main factor motivating employees to decide against established recommendations for the design of shift work schedules.

2) Employees were interested in ergonomic recommendations

There were many discussions on the recommended design of shift schedules, and employees were interested in research results. The major disputes were based on decisions about which aspects of the recommendations were most important, and how to reconcile these with employee preferences.

3) Employees were often aware of the consequences of their preferences.

In many cases, employees who preferred very demanding working time arrangements (for example, permanent night work, long hours) were well aware of the potential hazards for their health and safety.

4) Employees preferences are not only a question of income level

A preference for higher income over better arrangement of working hours was found in branches and positions ranging from relatively low salary (e.g., busdrivers) to positions with high salary levels (e.g., physicians in hospitals).

5) Often employers' preferences were not in conflict with employees' preferences

Employers typically were neutral with respect to 
arrangement of working hours as long as their staffing demand was fulfilled and overtime-supplement costs stayed the same or decreased. In cases in which the preferences of employees were in conflict with recommendations this was generally not due to pressure from the side of employers.

\section{DISCUSSION}

The main results of the above analysis were:1) in a substantial number of cases employees' preferences were in conflict with ergonomic recommendations and these conflicts were not only due to lack of knowledge, very low income or pressure of employers; 2) income was the main factor influencing employee preferences; and 3) works-councils or trade unions pressed for health and safety considerations only to a limited degree.

Considering these results, a regulatory approach that builds upon consent by employees, works councils or trade unions has shortcomings if there are preferences for 'unhealthy' schedules. Using the consent based approach, working hours that imply strong health and safety risks may be legally chosen. While in many cases the necessary consent of employees, works council or trade unions will ensure that exceptions are not applied if high risks are to be expected, this cannot be taken for granted.

One possible approach to overcome these shortcomings would be to make systematic risk assessment mandatory. In other areas of health and safety, the European Union regulation requires such an approach of systematic evaluation of health hazards at workplaces. This approach has some similarities to the approach to regulation pursued in countries such as Australia, where the focus of health and safety policy is currently risk management. This focus flows from the duties imposed on employers under legislation and common law to provide safe and healthy workplaces (and systems of work) and to control potential risks to the health and safety of employees (Occupational Health and Safety Act (Vic), 1985). Statutory bodies are in place to administer legislation and ensure compliance. The risk management procedure involves identifying, assessing and then controlling (i.e. by eliminating or minimising) the risks that are relevant to the particular workplace.

However, risk assessment of working hours is extremely difficult due to the variety of occupations, working conditions and other factors that must be considered, the complex interaction of the various factors involved and the long-term effects that must be considered. The risk management approach, if taken seriously, would also be extremely time con- suming if risk assessment had to be started from scratch in every case. Furthermore, the question of whether a satisfactory level of risk assessment has been reached or whether additional risk assessment is needed would have to be answered in each company. The question as to whether risks are sufficiently minimised is one that cannot be answered easily.

A regulation based on risk assessment also has the problem of 'control'. Given the variety of occupations and working conditions and the huge number of different shift schedules, statutory bodies would hardly be able to check compliance in every case. The complexity of the evaluation makes this even more unlikely.

The difficulties of risk assessment may, however, be reduced by research in the following areas:

\section{Research on the scope of applicability of recommendations}

Given that local solutions should consider recommendations, the discussion within the scientific community regarding the scope of applicability of recommendations becomes even more important. For example, given a study on 12 hours shifts of nurses, what are the relevant features of this situation and under which conditions can we decide whether a $12 \mathrm{~h}$ shift system in a different environment has similar benefits and disadvantages?

\section{Research informing the risk assessment process}

Given the prevalence of irregular working hours it seems sensible to work on a knowledge-map of risks. A detailed proposal for similar support for employers and employees has been proposed (Tepas ${ }^{13}$ ). Additionally, it seems sensible to continue work on the identification of risks and assessment of working hours (Jansen et $\mathrm{al}^{7}$; Schönfelder ${ }^{9}$ ).

\section{Approaches to regulation call for further research}

Given the shortcomings of both approaches and the complexity of the matter and the importance of the issue, research on approaches to the regulation of working hours is needed.

\section{ACKN O WLED G EMENTS}

The author thanks Martin Schürz, Shantha Rajaratnam, Beate Beermann and the anonymous reviewers for their feedback on earlier versions of this paper. 


\section{REFEREN CES}

1. Barton J, Smith L, Totterdell P, Spelten E, Folkard S. Does individual choice determine shift system acceptability? Ergonomics 1993;36:93-9.

2. Barton J. Choosing to work at night: a moderating influence in individual tolerance to shift work. J Appl Psychol 1994;79:449-54.

3. Colquhoun WP, Costa G, Folkard S, Knauth P. Shiftwork: problems and solutions. Frankfurt: Peter Lang; 1996.

4. European Union. Council Directive $93 / 104 / E C$ of 23 November 1993 concerning certain aspects of the organization of working time. Brüssel; 1993.

5. Freddie MAC. Consumer credit survey. McLean, VA; 1999

6. Gärtner J, Kundi M, W ahl S, Hörwein K, Herber G, Janke $M$ et al. Handbuch schichtpläne planungstechnik, entwicklung, ergonomie, umfeld. Zürich: ETH; 1998.

7. Jansen B, Kroon H. Rota-Risk-Profile-Analysis. $11^{\text {th }}$ International Symposium on Night and Shiftwork; 1994 Fev 8-13; Melbourne, Australia. Melbourne; 1994.

8. Knauth P. Design of shiftwork systems. In: Colquhoun PW, Costa G, Folkard S, Knauth P, editors. Shiftwork: problems and solutions. Frankfurt: Peter Lang; 1996. p. 155-73.

9. Schönfelder E. Entwicklung eines verfahrens zur bewertung von schichtsystemen nach arbeitswissenschaftlichen kriterien. Frankfurt: Peter Lang; 1992.
10. Smith L, Hammond T, Macdonald I, Folkard S. $12 \mathrm{~h}$ shifts are popular but are they a solution? Int J Ind Ergon 1998;21:323-31.

11. Smith L, Mason C. Shiftwork locus of control effects in police officers. $15^{\text {th }}$ International Symposium on $\mathrm{N}$ ight and Shiftwork; 2001 Sept 10-13; Hayama, Japan. Hayama; 2001.

12. Spurgeon A. Working time: its impact on safety and health. Geneva: International Labour Office; 2003.

13. Tepas D. Workware decision support systems: a comprehensive methodological approach to workscheduling problems. Theor Issues Ergon Sci 2003:4:319-26.

14. Wahl S, Musliu N, Angelova R, Slany W, Herber G, Janke M. Shiftplanassistant 4.0 - State of development. In: Hornberger S, Knauth P, Costa G, Folkard S, editors Shiftwork in the $21^{\text {st }}$ century: challenges for research and practice.Frankfurt: Peter Lang; 2000. p. 327-32.

15. Wedderburn A, editor. Guidelines for shiftworkers. Dublin: European Foundation for the Improvement of Living and Working Conditions; 1991.

16. Yadegarfar G, Mcnamee R. The "healthy shift worker effect" in the relationship between shift work and longitudinal change in blood pressure and body mass index. Ann Epidemiol 2003;13:585-6. 